\title{
15 Years of Pension Reform in Germany: Old Successes and New Threats
}

\author{
Holger Bonin \\ ZEW Mannheim and IZA, P.O. Box 1034 43, D-68034 Mannheim, Germany. \\ E-mail: bonin@zew.de
}

The article surveys the state of the German pension system after a sequence of reforms aimed at achieving long-term sustainability. We argue that the latest reforms have moved pension provision in Germany in principle from a defined benefit to a defined contribution scheme, and that this move has stabilised pension finances to a large extent. We furthermore argue that the real economy consequences of the global financial crisis create threats to the core success factors of the reforms - cutting pension levels and raising mandatory pension age. Finally the article discusses further possible reform measures, including the option to install a fourth pillar, providing income in retirement through working after pension age.

The Geneva Papers (2009) 34, 548-560. doi:10.1057/gpp.2009.20

Keywords: pension financing; financial crisis; fiscal sustainability survey; Germany

\section{Introduction}

Germany still has a generous pay-as-you-go public pension insurance with high effective replacement rates and low effective retirement ages. Nevertheless, through a long reform process that began in 1992, the paradigm of public pension provision has radically changed in response to the country's looming ageing crisis. In a nutshell, the path to improved public pension finances in Germany might be best described as a move from a defined benefit scheme to a defined contribution scheme.

After the last major amendment in 2007 that lifted the statutory retirement age to 67 , the debate about further pension reform measures basically had come to a halt. That the long-term financial stance of the first pension pillar had improved considerably became broad consensus. The current crisis in the financial sector, and the economic depression that is about to follow, however, have brought the pension system in Germany under political pressure again.

In the wake of the financial crisis, several threats which might lure decision-makers away from the reform path have emerged: (i) pressure to disconnect the annual adjustment of pensions from annual growth of wages, as average wage earnings are predicted to decline, and (ii) pressure to moderate the scheduled increase in mandatory retirement age, as employment opportunities are worsening also for older workers.

Against this background, this article seeks to provide a synthetic overview about the recent developments in the German pension system and their impact on current and future pension finances. The remainder is structured as follows. The next section briefly summarises the demographic ageing process in Germany and touches upon its economic consequences. The subsequent section analyses the recent reforms of the 
pension system. The penultimate section discusses the looming issues in a new pension reform debate that has emerged from the consequences of the global financial crisis. The last section concludes with some remarks on further reform steps needed.

\section{Demographic ageing and economic challenges}

Fertility rates in Germany have been low in international comparison ever since the baby boom. Despite substantial public spending on family-related transfers, most analysts do not expect a substantial increase over the current rate of 1.4 any time soon. The reason is a combination of various institutional arrangements preventing mothers from working full-time, and rather strong and persistent preferences of German parents to care for young children at home.

Poor fertility rates in combination with a continuous and almost linear trend of growing life expectancy will yield strong demographic ageing at least up to the year 2050. Old-age dependency ratios in Germany have already been increasing for some time, but the deterioration of the working-age population to retirement-age population ratio is predicted to accelerate considerably as of the year 2010. Börsch-Supan and Wilke ${ }^{1}$ calculate that the ratio of the population of age 65 or older to the population of age 15-64 will increase from 0.3 to about 0.55 through the year 2035 . From then on demographic ageing is expected to slow down. Yet the dependency ratio will continue to increase even when the baby boomer generations will have died - it will reach 0.65 in the year 2050. In other words, at the mid of the century under normal demographic circumstances 1.5 individuals at working age could live alongside one individual older than 65 .

The expected massive demographic change poses various economic challenges. To begin with, relative shortage of workers tends to reduce the returns to capital. A growing role for privately funded pensions, as a response to public pay-as-you-go pensions falling, may exacerbate demographic pressure on capital returns. Still, a demographically induced asset meltdown in Germany appears rather unlikely: increased demand for machines and other infrastructures to compensate labour shortages, as well as the possibility of hedging demographic risks on international capital markets, are factors dampening decline in capital returns. Börsch-Supan et al. ${ }^{2}$ simulate that demographic change will just reduce rates of return by around 16 per cent through the year 2030, even if a higher share of pension provision is shifted to funded schemes. They show that the main mechanism preventing asset meltdown is international diversification.

The more important challenges, then, are probably associated with labour markets. One dimension is sectoral changes that are associated with shifting demand patterns. For example, it is straightforward to anticipate that employment in health services will grow considerably, while demand for transport services (e.g. associated with commuting) will decline. According to some estimates in association with demographic

\footnotetext{
${ }^{1}$ Börsch-Supan and Wilke (2007).

${ }^{2}$ Börsch-Supan et al. (2006).
} 
impact on consumption patterns, as much as one in six jobs will shift between sectors in the course of the first half of the century.

Demographically induced sector change of course is not a phenomenon specific to Germany. Yet it seems that its labour market could be less ready to absorb this kind of shock than labour markets elsewhere. At least the labour market in Germany is still relatively rigid in international comparison, which shows in rather low levels of occupational, sector and geographical mobility of workers.

Another dimension is the decline in the number of workers available on the labour market. In the course of the demographic ageing process, the population at working age will begin to shrink about one generation (or 20 years) earlier than the population as a whole. If status quo labour market structures are maintained, aggregate labour supply is expected to decline from 42 to 33 million workers through the year 2050 , a decline by almost one quarter. Accordingly the ratio of pensioners to workers is expected to double from 55 per cent to 115 per cent. Thus each worker will need to support more than one retiree (besides his or her own children).

Yet there appears to be rather ample scope in Germany to offset the adverse labour market effects of demographic change. The number of workers does not only hinge on the age structure, but also on (especially female) labour force participation rates, unemployment rates, the average retirement age and the average age at entry into the labour market (and thus time spent in full-time education). In all these structural dimensions, the German labour market, in spite of the massive and effective labour market reforms begun at the turn of the century, still lags behind in international comparison. Average working life is rather short due to long education and early retirement. Labour supply of women is rather low, with regard to both participation and working hours. Structural unemployment remains rather high.

This means that the preconditions are better in Germany than elsewhere to foster future employment through further labour market reform. The key is a boost of the female labour force participation rate: if it were possible to raise it to 90 per cent of the male rate, the work force would increase by almost 9 per cent compared with a status quo scenario. Higher female labour force participation requires abandoning current tax and social welfare legislation in favour of the single - male - bread winner model, and reducing the cost of external childcare. Altogether, Germany would prevent as much as 60 per cent of the future employment decline if it managed to adapt to the employment parameters of a high employment rate country like Denmark. ${ }^{3}$

However, if Germany were not to be as successful as planned with regard to boosting up employment rates, demographic change might put strong pressure on consumption opportunities and thereby sustainability of pension finances. Under status quo conditions, production per worker needs to increase by the margin of 18.5 per cent through the year 2035, in order to compensate the pure loss in the number of workers. In other terms, this requires an additional productivity gain of around 0.7 per cent per annum. In a high-productivity country like Germany, this number clearly appears out of reach.

\footnotetext{
${ }^{3}$ See Börsch-Supan and Wilke, 2007.
} 
From this outlook a need to adapt social insurance schemes emerges, in order to shield them against the economic consequences of demographic change. Over the past years, Germany has indeed progressed in this direction, at least regarding its pension system. ${ }^{4}$

\section{Recent changes in the pension system}

The statutory first pillar of the German pension system operates on a pay-as-you-go scheme. Up to the year 2008, the revenue side of the public pension insurance benefitted greatly from the strong decline in both cyclical and structural unemployment in Germany. Decline of the latter seems to be associated with major reforms of the social welfare system targeting the long-term unemployed, which generated a growing number of jobs subject to Social Security. In addition, revenue grew because of a slight lift of the contribution rate to 19.9 per cent of gross wages.

At the same time, pension expenditure growth has been very moderate for several years. Two driving forces are behind this development. First, the low growth in (average) wage earnings, a key source of Germany's new employment success, immediately translated into low pension increases. This effect comes from wage indexation built into the statutory formula used for annual uprating of pensions. Second, some moderating factors that were amended to the pension adjustment formula in order to achieve a lower replacement rate (i.e. the ratio of pension and wage levels) began to have an effect. Individual pensions in gross nominal terms thus were effectively frozen in some years. ${ }^{5}$ Total individual pension growth over the period 2005-2008 translated into a per annum rate of only 0.41 per cent.

As a result of improving revenues and moderate expenditure growth, the public pension insurance scheme had managed to rebuild its reserves for cushioning shortterm fluctuations when the global financial crisis set in. This fund had almost been exhausted 2 years before.

If one looks beyond the short-term improvement of pension finances, the perspective of long-term financial stabilisation despite the severe demographic ageing process ahead appears even more remarkable. The path to sustainable public pension finances in Germany was laid through a radical change in the paradigm of pension provision, which, tolerating a certain degree of simplification, might best be characterised as a move to a defined contribution scheme. In a defined contribution scheme, pension levels adjust endogenously to follow revenue, at least up to the point

\footnotetext{
${ }^{4}$ Altogether, reforms to stabilise the public health and long-term care pay-as-you-go insurance schemes have been less successful. These systems, on the one hand, are less affected by demographic change, as retirees have to pay contributions from their pension income. On the other hand, however, these systems come under particular pressure due to the rising population share of the oldest. Per capita spending growth is stronger than GDP growth due to technological progress, but also due to inefficiencies in health and long-term care provision, which exacerbates the demographic pressure. For a thorough assessment of the long-term financial sustainability of these systems, see Hagist (2008).

${ }^{5}$ This of course implies a decline of individual gross pensions in real terms. Furthermore, individual pensions declined in net terms, as contribution rates to statutory health and long-term insurance paid on pension income were raised.
} 
that the income provided through Social Security does not fall below a minimum standard.

Before, the public pension pillar in Germany basically had a defined benefit scheme in place, with contribution rates following defined expenditure needs. Up to the turn of the last century, pensions were indexed such as to guarantee a replacement rate of roughly 70 per cent in terms of net wages or roughly 48 per cent in terms of gross wages. But the pension reform of 2001 introduced contribution rate ceilings for the first time ( 20 per cent up to 2020, and 22 per cent up to 2030). In order to achieve these goals, the reform launched moderate changes in the pension indexation formula that serves to link annual changes in pension levels to annual changes in wage levels. ${ }^{6}$ Although the adjustment soon was revealed as too soft to stay within the contribution rate limits, the attempt clearly prepared the gradual transition to a defined contribution scheme.

The decisive step was made in 2004 with the introduction of the so-called sustainability factor into the pension formula. This factor makes the current value of pensions a function of the ratio of pensioners to contributors in the system. Broadly speaking, the formula is designed so that supposed constant wages increase in the pensioner ratio by $x$ per cent will decrease the pension level by $1 / x$ per cent, that is by an inverse proportion.

The new design has two noteworthy features: first, the approach taken reflects a compromise concerning intergenerational redistribution. By means of an additional weighting factor, changes in the pensioner ratio do not fully translate into a lower replacement rate, as in a true defined contribution scheme, but only to a certain extent. However, the current weighting factor is set so that it generates, according to realistic projections, only moderate contribution rate growth. Up to the year 2030, the contribution rate is to increase by two percentage points, which corresponds to a replacement rate of 46 per cent. For a comparison, a constant contribution rate corresponds to a replacement rate of 37.5 per cent, which would be clearly below the fixed legal minimum standard of 43 per cent.

Second, the formula is expressed in terms of a ratio of hypothetical "standard" pensioners and contributors, rather than an old-age dependency ratio. Although these ratios are of course closely correlated, it may happen that pensions grow, for example in a situation of improving labour market conditions, which renders minor employment relationships less frequent so that pensions grow despite old-age dependency deteriorating. This situation, which was clearly overlooked by the pension reformers, has indeed occurred in the year 2007. Similarly, if the participation or rather

\footnotetext{
${ }^{6}$ In brief, the individual pension entitlement in Germany is calculated as follows. First, for each year of contributions, the individual wage earnings are put in relation to the wage earnings of a benchmark individual with average earnings. Second, the figures computed in the first step are summed up considering the entire years of contributions of an individual. Third, the figure calculated in the second step is multiplied with a benchmark pension value, which is representative for a benchmark individual with average earnings and 40 years of contributions. The resulting entry pension value is updated each year by using an indexation formula that ties the benchmark pension value to the average gross wage growth among contributors in the previous year. In addition some adjustment factors have been introduced, which are explained in the main text.
} 
employment rates in the working-age population increased, not only the contribution rates would fall in line with growing revenue growth, but also the replacement rates would fall by less according to the changing sustainability factor.

For the reason explained before, the long-term prospects of the public pension pillar in Germany are greatly improved by the additional decision of gradually raising mandatory retirement age from 65 to 67 years, which was taken in the year 2007. To be exact, starting from the year 2012 and with the birth cohort of 1947, the mandatory retirement age is scheduled to increase by 1 month per year and birth cohort. This means that the birth cohort of 1958 has to work up to the age of 66 . By the year 2029, the mandatory retirement age will reach the target age of 67 for all birth cohorts born from the year 1964.

Altogether, this step is predicted to lower contribution rates, improve the net replacement rate (through the sustainability factor effect) and only slightly reduce the predicted internal rate of return to pension insurance contributions.

Yet the timing and the exact quantity of these effects will depend on how individual labour forces or retirement behaviour will respond to the reform. The German pension system allows individuals to retire voluntarily at any time within a time frame of 36 months before the mandatory retirement age. However, an important amendment to the pension formula that has been gradually introduced since the late 1990s implies that individuals who retire early must accept a reduction of the pension level of 0.3 per cent per month of early retirement.

After this reform, the aggregate pension loss associated with early retirement can be quite substantial given that the conditional life expectancy at retirement age is above 15 years and still growing. In principle, to the extent that the pension cut associated with early retirement is actuarily fair, this does not affect the total inter-temporal fiscal impact of the reform. Yet individuals in practice may still decide to retire early especially if they have a high preference for leisure or a short individual life expectancy. Furthermore, the financial penalty for early retirement is not effective for those mostly low-skilled individuals whose pension value is at or below the social welfare level. Finally, unemployment moves the balance in the direction of early retirement, since reemployment chances of the elderly unemployed are very low in Germany. ${ }^{7}$ The effective benchmark income that enters into the retirement decision thus becomes unemployment benefits instead of wage earnings.

In this context, it is worth noting that the steps forward made in the pension system have been supported by complementary steps in the German unemployment insurance system. As part of the thorough labour market reforms aimed at boosting employment, special regulations that extended the payment of unemployment benefits up to 27 months (as compared to the regular 12 months) were abolished. In effect, this measure has barred a special path into early retirement at age 60 on the condition of long-term unemployment. At the same time, employment rates in the age range 57-60 have markedly grown recently, which indicates that this strategic possibility indeed had been used.

\footnotetext{
${ }^{7}$ Zwick (2008).
} 
In the current framework, strategic behaviour, in order to circumvent early retirement penalties, still appears a relevant possibility. Even now individuals can enter into early retirement without a penalty through disability pensions. In view of the clear incentives at work, it will be necessary to more sharply control this channel in the future.

The ongoing transformation of the German pension system is not fully understood without looking at the very dynamic development of its second and third pillars. In fact, the substantial decline in public pensions caused by the shift to a defined contribution scheme is expected to be offset by supplementary occupational and private pensions. In order to achieve this aim, supplementary pensions are subsidised, either by tax deferral or tax deduction, or by direct subsidies to individual and occupational pension plans. These supplementary pensions are, however, not mandated.

The recent pension reforms remained largely undecided on the role of occupational pensions vs. individual accounts, though occupational pensions, underdeveloped in Germany in international comparison, might substitute for mandated private pensions from a psychological perspective.

To promote occupational pensions, there is now a right to convert part of the salary directly into pension plan contributions. In practice, arrangements vary widely. Eligibility and subsidy regulations are complex. For example, there are different tax treatments and investment regulations depending whether arrangements are based on gross pay or net pay. Some evidence suggests that the subsidy scheme to promote occupational pensions has fuzzy and perhaps unwanted distributional implications.

Furthermore, collective bargaining agreements have precedence over the individual right to convert salary. This means that employers and unions can impose their rules on occupational pension plans, which may be in conflict with individual workers' preferences. It is difficult to say whether or not the resulting reduction of transaction costs compensates for this disadvantage.

The new individual pension plan pillar, the so-called Riester pension, seems to have taken off after a sluggish start, despite the many restrictions that apply. The main restriction is on payment plans. Incentives in terms of direct savings subsidies or, alternatively, treatment of retirement savings as tax deductible special expenses, are only provided for investment vehicles that guarantee payment of a life annuity payable from retirement, but there are many more preconditions that need to be fulfilled to qualify for a Riester pension plan.

It appears that decision-makers have begun to realise that the individual savings pillar is over-regulated and will eventually loosen some of the restrictions in order to promote the instrument further. A much advertised first step in this direction is the recently introduced possibility to employ Riester savings plans to acquire a personal dwelling.

The idea behind this measure is that private homeowners require less income in oldage because their property creates a return either in terms of rent-free lodging or the possibility to liquidate the asset. Yet, at closer inspection, the efficiency of the new regulation appears less obvious. First, it is far from clear that investment into a private dwelling creates a return comparable to that of an investment on the financial assets. At least both housing prices and rent tend to come under pressure as demographic ageing is associated with population decline, unless the trend of growing housing 
demand per capita would counterbalance the demographic trend. Furthermore, there are hardly any possibilities to hedge the investment risk associated with a single private dwelling, in contrast to the diverse possible diversification strategies on financial markets.

Second, the acquisition of housing for private use is subsidised, like any other pension plan. This implies the possibility of rather deadweight losses, that is, the change in private homeownership rates at the margin could be very small. At least this seems to be an experience with other fiscal subsidy programmes on home ownership. ${ }^{8}$ In fact, one might argue that the recent amendment of the Riester pension rules mainly serves to reintroduce another private home ownership programme abandoned in 2007 through the back door. ${ }^{9}$

Despite these critical remarks, one may see this recent amendment just as a first step to permit other valid forms of provision for old age under the heading of the Riester pension scheme in the future.

\section{New debates in the aftermath of global financial crisis}

After the decision to introduce the long-term increase of mandatory retirement age, the public debate about the pension system lost much impetus. This has changed since autumn 2008, with the emergence of the global economic crisis. Of course, the open scenes of fire first on the financial market and increasingly in the real economy dominate the discussions about proper government intervention. Yet a debate whether the pension system requires readjustment in the aftermath of the financial crisis appears to be gradually emerging.

This debate must be seen as part of a discussion on the fundamental merit of market-oriented economies, which has brought to the fore some proponents of state intervention. In fact, public opinion in Germany has changed to become rather sceptical about the gains associated with the deregulation of recent years, despite its perceptible positive effects. Decision-makers in turn have started to go back on some of the reforms or to introduce measures aimed at offsetting alleged negative effects. It is in this spirit that unemployment benefits for older workers have been expanded once again, or that minimum wages have been imposed upon some sectors of the economy.

The new pension discussion is generally not about the second and third pillars. As funded pension plans are just emerging in Germany, and the generally very conservative savings behaviour of Germans, the loss of asset values so far does not much affect income prospects of pensioners. Moreover, due to comparatively prudent financial market regulation (and prudent regulation of private and occupational pension plans), the threats work more through the real part of the economy, that is, the wage and employment losses associated with the induced recession.

\footnotetext{
${ }^{8}$ Van Ewijk et al. (2007).

${ }^{9}$ Admittedly, the distributive impact of the two subsidy schemes is somewhat different, as different income thresholds are involved. The Riester subsidy altogether is less generous.
} 


\section{A ban on nominal pension cuts?}

In this climate, a seemingly urgent demand to interfere with pension finances has emerged. As a consequence of the deep economic depression expected for the year 2009, nominal wage earnings are predicted to decline on average. According to the established rules of the first pension pillar, nominal pensions would need to decline as well.

Faced with this situation, the government has decided to introduce an amendment that prevents any nominal pension cuts as of 2010. This decision breaks with a cornerstone of Germany's first pillar, the dynamic pension link of pensions to wages that lets pensioners share in productivity and welfare growth. Within this logic it is obviously inconsistent to stipulate an asymmetry, making pensioners relatively better off in a phase of nominal wage decline.

The rule is to the disadvantage of younger generations who will need to pay higher contributions compared to the previous state of legislation. This is true even if extra spending were paid through additional federal contributions to the first pillar. These would just yield either extra deficits or extra taxes, mostly accruing to the younger generations.

An even more fundamental concern about the amendment is that it is at odds with the guiding principle of the last pension reforms in Germany, namely to reduce the replacement rate. Suppose average wage earnings of the contributors to the pension system were to decline by 1 per cent. With constant pensions, the pension level would then increase by 0.5 per cent. In other words, some recent achievement in stabilising long-term pension finances would be lost.

This is a serious concern despite the promise made by the government that it would catch up on the moderation of pension growth later, when average wages of the contributors are growing again. This commitment does not seem especially credible, as it has been made before. Already in 2005, 2006 and 2008, the government raised pensions by more than originally implied by reformed pension legislation. As a result the discount factor required in order to keep up with the originally planned replacement rate was already large before the last amendment. Because of this background, if the nominal pension guarantee further raised pension levels, the necessary extra discount factor as of 2011 would be politically difficult to implement.

\section{Retire earlier or work longer?}

In summer 2008, the German labour market was in a very healthy state. Unemployment had reached its lowest level in two decades. The average duration of unemployment had fallen by half in a very short time. The rapid positive labour market development stemming from a fortunate combination of structural reform and improvement over the business cycle might explain why the bold move to raise mandatory retirement age did not face too much opposition at the time it was made.

With employment prospects worsening, the scheduled increase in mandatory retirement age has come under pressure again. Pointing to the rising level of unemployment, which seems especially pronounced among the elderly not the least due to non-age neutral firing regulations, critical voices are becoming louder. Their 
fundamental arguments against a mandatory retirement age of 67 years put forward are the same used to justify generous early retirement rules that came into being in the wake of the oil crisis during the 1970s. First, elderly workers could not find employment, and second, if they were employed, it would take away employment opportunities from younger individuals.

This reasoning first of all overlooks the long transition period bringing the reform into full effect only from the year 2030. Its gradual unfolding leaves the actors on the labour market enough time to adapt to the new structural conditions. For example, investment into training of elderly workers or other productivity-preserving measures can be expected to grow. This expectation comes from growing returns on this investment, if workers can be safely expected to withdraw from the labour market at an older age.

Second, older workers appear as weak substitutes for younger workers. ${ }^{10}$ Thus it is not too surprising that there is no strong empirical support for the hypothesis that the massive early retirement policies of the past helped improving employment opportunities of younger workers in Germany. At the same time, there is substantial evidence supporting the hypothesis that the early retirement policy weakened the employment possibilities of older workers.

Third, the future demographic development itself facilitates the scheduled prolongation of working life. The massive decline in the population at working age will induce employers to search harder and pay more for older workers, whereas the better wage and employment opportunities will keep them participating in the labour market.

A proposition related to the demands to preserve the mandatory retirement age of 65 years is to allow that at least workers with long contribution histories can retire early. A conceptual argument against this approach is that it breaks with the equivalence principle that two individuals with the same lifetime contributions should have the same benefits from the system. The proposal puts individuals who pay higher contributions over a shorter life span in disadvantage. An empirical argument is that already the current exemption of individuals with more than 45 years of contributions from the increase in mandatory retirement age is costly. According to the German Council of Economic Advisors, ${ }^{11}$ in contribution rate terms, the price it has for the insured is 0.3 per cent of gross wage earnings.

In this context, it is worth noting that with the move to increase mandatory retirement age for all individuals, the pension reformers basically stepped away from ideas to foster voluntary employment after pension age. In fact, a number of experiences suggest that, in the German case, resorting to such a "fourth pillar" could be much less effective than a general lift of the retirement age.

First of all, the present share of individuals older than pension age and employed in jobs paying a wage subject to social insurance contributions is hardly measurable. Employment after mandatory retirement age basically takes forms that allow evasion from the public pension scheme: self-employment and minor employment (the so called "mini jobs") exempted from contributions to the first pillar. This is a rational behaviour considering the rate of return disadvantage associated with Pay-As-You-Go

\footnotetext{
${ }^{10}$ Card and Lemieux (2001).

${ }^{11}$ German Council of Economic Advisors (2007).
} 
financing. From this perspective it appears that bringing all labour earnings under the first pillar is a precondition for a successful fourth pillar. Such a change is not in sight, as it has massive legal and political obstacles.

With the introduction of the pension reduction for each month of early retirement, a pension increase (of 0.7 per cent) for each month of late retirement was also introduced. At present extremely few individuals choose this option, although the associated pension upgrade is close to actuarially fair. A higher upgrade might draw more individuals into working longer, yet it would not improve pension finance in an inter-temporal perspective. On the contrary, additional contributions while the individual is working would amount to less than the additional pension received in the remaining years of retirement. This would make the first pillar less sustainable.

One may argue that the arrangement described before is not successful because it does not fit individuals' preferences, who would rather like to enjoy some retirement benefits and at the same time work part-time or withdraw from the labour market gradually. Part-time retirement arrangements actually have been tested in Germany, but without great success. In an age window before pension age, individuals could receive government transfers compensating most of the earnings loss if they reduced working hours and gradually entered into retirement. These government transfers were taken up by a large share of individuals, who still overwhelmingly chose a specific "block arrangement". This arrangement allowed working full-time in the first half of the programme, and working zero hours in the second half. As the overall income obtained throughout the programme is the same under the block arrangement and a part-time arrangement, this behaviour clearly reveals that Germans have strong preferences for not combining retirement and work. This observation fits that their general preference for leisure time is high in international comparison.

In sum, it appears that the option of a fourth pillar built upon working beyond pension age is probably not an appropriate one for Germany. In the current situation, it will be definitely more important to defend the great achievement of the ambitious increase in mandatory retirement age, which improves sustainability of the public pension system directly.

Even if the current economic crisis is strong, it does not warrant giving the longterm perspective for frantic (and false) steps back. Here it helps to note that the impact of the increase in mandatory retirement age, if it works, goes beyond the pure mechanics of changing the effective old-age ratio in the pay-as-you-go budget formula. Often overlooked are the long-term growth effects of this step. According to Germany's Board of Economic Advisors, the induced higher labour supply raises the production capacity in the economy by $0.1-0.3$ percentage points during the period 2012-2029. In cumulative terms, this is a very substantial potential growth effect.

\section{Outlook}

It can be said that on the whole that the sequence of pension reforms in Germany has successfully converted what was once a monolithic Bismarckian public insurance system to a true multi-pillar system. In the current situation of economic turmoil, the core challenge at present is to protect what has been accomplished with regard to 
long-term financial sustainability against demands from the public to soften the reforms. Any step back taken now in the name of short-term crisis intervention will demand an even larger step forward as soon as the economy recovers in the future.

Still in the next period of calmer economic waters, pension reformers should tackle pending issues.

A first issue is integration of the East and West German public pension schemes that are still separated 20 years after re-unification. On the revenue side, the earnings threshold to compute maximum contributions is lower in the east, whereas on the expenditure side, wage indexation of nominal pensions is based on region-specific wage growth. Furthermore, pension contributions of East Germans are given a higher weight, as a means to compensate for lower average earnings level in the East. But application of this factor induces inequality: an East German who pays the same amount of contributions as a West German will receive a higher pension.

When these special regulations were introduced, the expectation was that East German wage levels would converge to West German wage levels soon. In this case, pension levels calculated according to the existing regulations would converge as well. But now average earnings in East Germany still are 15 per cent below the West German level, whereas average pension levels are above. The latter is a result of more complete work histories inherited from the communist era but also of the described pension regulations.

As the economic convergence progress has stopped, special treatment of East Germany is increasingly questioned. In fact, it is alien to the German pension system to remedy regional disparities. Within the West German scheme, there is a uniform treatment of contributions, although low-income regions and high-income regions co-exist. A simple method to integrate the East and West German pension schemes is basically the establishment of a common pension value.

A second issue, which will be more difficult to resolve, relates to provision of pension income for the low-skilled. As Riester pension plans are growing, it becomes obvious that they are not taken up by the poor. Building up personal funds for individuals with low and probably unstable labour income is unattractive. The tax benefit linkage in the public pension scheme is weaker for the population at the bottom end of the wage distribution that benefits from a built-in minimum pension guarantee. This guarantee implies that the transition to the defined contribution scheme reducing replacement rates reduces public pensions relatively less for poorer agents. Furthermore, the current legislation requires that individuals who become long-term unemployed first have to spend savings accumulated in a Riester pension plan before they can claim social welfare. This clearly reduces the incentive to invest into private provision for old age for individuals with a high long-term unemployment risk.

The public debate on how to adapt the system for low wage earners with unstable employment histories has not yet really begun.

\section{References}

Börsch-Supan, A., Ludwig, A. and Winter, J. (2006) 'Aging, pension reform, and capital flows: A multi-country simulation model', Economica, London School of Economics and Political Science, 73(292): 625-658. 
Börsch-Supan, A. and Wilke, C. (2007) Szenarien zur mittel- und langfristigen Entwicklung der Anzahl der Erwerbspersonen und der Erwerbstätigen in Deutschland, MEA Discussion Paper 153-07, Mannheim, Germany.

Card, D. and Lemieux, T. (2001) 'Can falling supply explain the rising return to college for younger men? A cohort-based analysis', Quarterly Journal of Economics 116: 705-746.

Hagist, C. (2008) Demography and Social Health Insurance - An International Comparison Using Generational Accounting, Baden-Baden, Germany: Nomos Verlagsgesellschaft.

The German Council of Economic Advisors (2007) Annual Report 2007/2008: The Gains Must Not Be Squandered, press release, 7 November, Wiesbaden, Germany.

Van Ewijk, C., Jacobs, B. and de Mooj, R. (2007) 'Welfare effects of fiscal subsidies on home ownership in the Netherlands', De Economist 155(3): 323-336.

Zwick, T. (2008) The Employment Consequences of Senority Wages, ZEW Discussion Paper No. 09-005, Mannheim, Germany.

\section{About the Authors}

Holgor Bonin is head of the department "Labour Markets, Human Resources and Social Policy" at ZEW Mannheim. Holger has vast experience as a scientific advisor to institutions including the European Commission, the UNDP and several Ministries in Germany. The focus of his academic research is applied labour economics. In particular, he studies labour supply, wage and employment rigidities, the economic impact of demographic change and migration and individual risk preferences. 